\title{
CAMINHOS PARA OUTRA INVESTIGAÇÃO EDUCATIVA E SOCIAL NO CONTEXTO AMAZÔNICO: aproximações possíveis e necessárias
}

\author{
CAMINOS PARA OTRA INVESTIGACIÓN EDUCATIVA Y SOCIAL EN EL CONTEXTO \\ AMAZÓNICO: aproximaciones posibles y necesarias
}

\section{PATHWAYS FOR ANOTHER EDUCATIONAL AND SOCIAL RESEARCH IN THE AMAZON CONTEXT: Possible and Necessary Approaches}

Juliane Corrêa $^{1}$

\section{RESUMO}

A escolha de "Caminos y derivas para otra investigación educativa y social" para compor essa publicação, no formato de resenha, foi devido às suas possíveis contribuições para investigações realizadas e a serem realizadas na região Amazônica. Seus autores ao abordarem questões ontológicas, epistemológicas e metodológicas, assim como questões referentes à ética e à divulgação científica no contexto da investigação educacional, explicitam pontos pertinentes ao crítico momento que estamos vivenciando no campo educacional e social. Além disso, apresentam uma confluência de uma diversidade significativa de experiências e indagações, um movimento de inclusão decorrente da articulação de grupos de investigadores de 11 Universidades da Espanha e uma disposição para ir mais além.

PALAVRAS-CHAVE: ontoepistemologia, metodologias de investigação, divulgação científica, ética e pesquisa educacional

\section{RESUMEN}

La elección de "Caminos y derivas para otra investigación educativa y social" para componer esta publicación, en formato de reseña, se debió a sus posibles aportes a las investigaciones realizadas y por realizar en la región amazónica. Sus autores al abordar cuestiones ontológicas, epistemológicas y metodológicas, así como las cuestiones relacionadas con la ética y la divulgación científica en el contexto de la investigación educativa, plantean cuestiones pertinentes al momento crítico que vivimos en el ámbito educativo y social. Además, presentan una confluencia de una diversidad significativa de experiencias y preguntas, un movimiento de inclusión debido a la articulación de grupos de investigadores de 11 Universidades de España y una voluntad de ir más allá.

PALABRAS CLAVE: ontoepistemología, metodologías de investigación, divulgación científica, ética e investigación educativa

Submetido em: 05/01/2021 - Aceito em: 13/01/2021 - Publicado em: 25/01/2021

1 Professora Associada do DMTE. Coordenadora do GRÀOS - pesquisa e desenvolvimento em experiências educativas mediadas pelas TICS 


\section{ABSTRACT}

The choice of "Paths and drifts for another educational and social investigation" to compose this publication, in the format of a review, was due to its possible contributions to investigations carried out and to be carried out in the Amazon region. Its authors when addressing ontological, epistemological and methodological issues, as well as issues related to ethics and scientific dissemination in the context of educational research, present questions pertinent to the critical moment that we are experiencing in the educational and social field. In addition to presenting a confluence of a significant diversity of experiences and questions, a movement inclusion due to the articulation of groups of researchers from 11 Universities in Spain and a willingness to go further.

KEYWORDS: ontoepistemology, research methodologies, scientific dissemination, ethics and educational research

\section{INTRODUÇÃO}

A realização de pesquisas educacionais e sociais no contexto da Região Amazônica consiste num grande desafio que apresenta questões ontológicas, epistemológicas, metodológicas e éticas para os processos investigativos normalmente desenvolvidos na tradição acadêmica educacional. Esse desafio precisa ser explicitado e abordado de uma forma mais ampliada para que se possa desenvolver uma sensibilidade, uma proximidade outra que possibilite a descolonização de relações instituídas historicamente entre o Brasil e a região Amazônica. Sendo assim, podemos explicitar a necessidade de que, a partir de uma outra escuta, de um outro olhar, de uma outra epistemologia, possamos sustentar este contato com o outro, que nos afeta, irrompe, atravessa, destituindo o lugar confortável de pesquisador, à medida que esse outro nos interpela a habitar uma relação (LEVINAS, 2011) que visibiliza nossa vulnerabilidade, nossa condição humana.

De fato, como pesquisadores temos de estar atentos para que possamos constituir uma relação investigativa sem colonizar, sem impor uma gramática ou uma percepção já instituída como hegemônica, até mesmo, proveniente de outras regiões do país. Por isso, considero que a obra

Caminos y derivas para otra investigación educativa y social pode nos apontar possíveis tangenciamentos, riscos e aproximações, a partir de um diálogo com reviravoltas ontológicas e epistemológicas que podem auxiliar a não transformar as experiências, os conhecimentos que surgem nos diversos contextos de vida e nas diferentes práticas educativas que nos escapam em narrativas atualizadas de colonização do outro. 


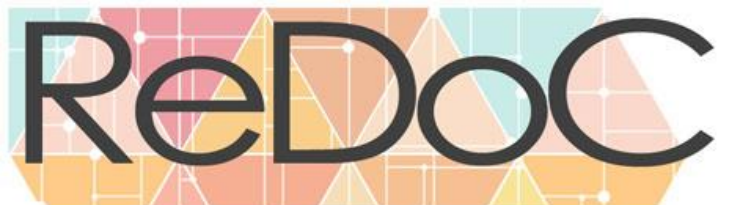

\section{Revista Docência e Cibercultura}

Ao longo de uma investigação realizamos várias escolhas que são demandas e influenciadas pela realidade pesquisada. Da mesma forma, nesta resenha, algumas escolhas foram feitas e um delas foi por incluir todos os autores e autoras, de modo a explicitar que estamos coletivamente construindo dados, pois conforme Kastrup (2015, p.33) "não há coleta de dados, mas, desde o início, uma produção dos dados da pesquisa", ou seja, estamos construindo narrativas, representações, percepções acerca de contextos, pessoas e relações. Para que isso não se transforme num processo de colonização, precisamos estar atentos frente às lacunas e limitações que encontramos no campo da investigação educacional e social que, por vezes, retratam formas de fazer e de pensar provenientes de nossas relações sociais. Nosso desafio consiste em como podemos ir além no contexto educacional Amazônico, explicitando nossas concepções de mundo e de ser humano, o que nos remete às questões ontológicas; de produção de conhecimento, o que nos remete às questões epistemológicas e de como fazer, escolhendo procedimentos que nos remetem às questões metodológicas. $\mathrm{E}$ devido a esse conjunto de ponderações, considerei pertinente compartilhar, por meio desta resenha, a publicação Caminos y derivas para otra investigación educativa y social.

Os coordenadores dessa publicação, Juana Maria Sancho Gil, Universidad de Barcelona; Fernando Hernández Hernández, Universidad de Barcelona; Lourdes Montero Mesa, Universidade de Santiago de Compostela; Juan de Pablos Pons, Universidad de Sevilla; J, Ignacio Rivas Flores, Universidad de Málaga e Almudena Ocaña Fernández, Universidade de Granada, representam uma articulação de grupos de investigação cujas temáticas são essenciais para que possamos rever nossas práticas investigativas, principalmente, neste momento tão complexo, tão devastador, mas ao mesmo tempo tão frutífero para a construção e realização de novas perspectivas. Os autores situam o campo de estudo abordado referente às problemáticas da investigação educacional e compartilham um conjunto de questões a partir do diagnóstico de que existe uma crise da investigação educativa, caracterizada tanto pela desconexão entre investigação e prática educativa, como pela incoerência ontológica, epistemológica e metodológica. A publicação foi cuidadosamente organizada em três partes, de modo a compartilhar diferentes possibilidades de investigação em torno de questões que agrupam experiências e estudos de 54 pesquisadores motivados e comprometidos com a construção e realização dessas novas perspectivas. 
Os sete capítulos que compõem a Parte I - Ontoepistemologías emergentes: de aquello que no se puede separar estão agrupados em torno da questão ontológica e epistemológica, expressando o compromisso com uma pedagogia conectada com a vida humana e com o mundo material. Desta forma, Sancho e Benavente em Reexplorando "la materia": implicaciones para la investigación educativa y social alertam para as implicações de novas perspectivas investigativas que nos conduzem à necessidade de uma permanente contextualização das relações educativas, a qual, por sua vez, nos expõe a um devenir pedagógico marcado por interrupções e diferenças decorrentes dos conhecimentos produzidos nestas relações e Carrasco e Varela em Más allá de la máquina antropocéntrica: hacia una educación e investigación pós humanistas alertam para uma superação da visão antropocêntrica, da oposição natureza e cultura, de modo que tenhamos uma intra-ação na qual se relacionam humanos, não humanos e materiais. Ambos textos apresentam uma nova perspectiva para abordar o fenômeno educativo, superando a separação sujeito/objeto e permitindo emergir novas metodologias.

Algumas implicações dessa perspectiva são expostas por meio das viradas afetiva, decolonial, feminista, inclusiva e do self que perpassam outras formas de conceber e conduzir os processos investigativos. Em La investigación poscualitativa: origen, referentes $\boldsymbol{y}$ permanente devenir Correa, Aberasturi-Apraiz e Gutiérrez-Cabello destacam a questão da virada afetiva, do papel dos afetos na pesquisa qualitativa e a virada linguística expressando um questionamento da representação da linguagem e as possibilidades da escritura como método de investigação; em Perspectiva decolonial de la investigación educativa y social: rompiendo con la hegemonía epistemológica, Flores, García, López e León reconfiguram, a partir da virada decolonial, a noção de conhecimento frente às relações de poder, de subalternidade e do sujeito, portanto se posicionam contra o capitalismo, patriarcado e colonialismo; em El giro feminista: "No es oro todo lo que reluce”, Pilar Ballarín destaca a virada feminista e centra no impacto produzido na ciência pelas mulheres, pelos diferentes tipos de feminismos; em El giro inclusivo en la investigación socioeducativa de Alba e Nind temos a virada inclusiva que aborda a transformação da investigação sobre pessoas com necessidades especiais para a investigação com elas de modo a incluir seus interesses e seus 


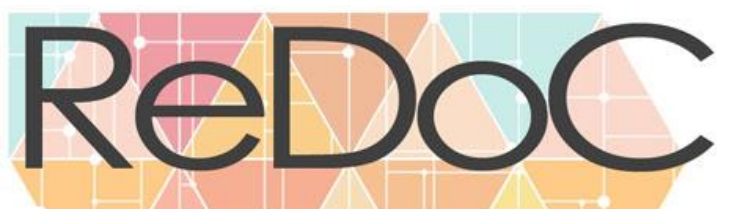

\section{Revista Docência e Cibercultura}

pontos de vista; por fim, em Las epistemologías del self, Rifà-Valls e Tarrés destacam a virada na investigação educativa e social em relação à compreensão do sujeito na construção do conhecimento, enquanto epistemológicas do self, compreendendo a subjetividade como fenômeno de agência, como capacidade de ação.

Braz (2016), em sua monografia de conclusão de graduação no curso de Formação Intercultural para Educadores Indígenas, nos apresenta o Tehêy da comunidade Pataxó do sul da Bahia e, pouco a pouco, vai nos introduzindo na sua visão de mundo, na sua concepção ontológica, nos apresentando a epistemologia e metodologia de sua comunidade, por meio da qual as crianças vão aprendendo a pescar os "saberes de manejo da vida", vão amassando as palavras e o conhecimento", afinando o ouvido e a visão de modo a "ouvir a espiritualidade da voz do seu povo." E para "amassar" essa nossa relação com o outro, compreender uma outra existência, precisamos vivenciar e compreender o que Ellsworth (2005, p.30) aponta como um lugar onde temos "nem eu nem outro, mas a realidade da relação", onde "o mundo e eu existimos em diferença, em encontro", onde teremos a possibilidade de encontrar uma experiência " em transição e em movimento em direção a formas até então desconhecidas de pensar e estar no mundo"(Ibid., p.16). De forma semelhante, Semetsky (2010, p.477) nos diz que podemos reconhecer essa experiência como encontro, contextual e, portanto, única, onde "Eu não me encontro do lado de fora. Eu encontro o outro em mim.”, pois cada encontro é "um evento experiencial singular", onde algo se passa para além de mim. (traduções da autora da resenha). Considero que as diversas questões ontológicas e epistemológicas abordadas pelos autores nos permitem incorporar a dimensão relacional, possibilitando um espaço para visualizar o que se passa, o que sentem e o que propõem as pessoas envolvidas, de modo que possamos captar, por meio de perspectivas metodológicas outras, como estão sendo afetados na dimensão de sua sensibilidade humana, na sua existência humana, na sua relação de proximidade (LEVINAS, 2011), de resistência e de construção e manutenção do vínculo social.

Na Parte II - Perspectivas metodológicas encontramos com 27 pesquisadores compartilhando suas perspectivas investigativas, construindo novas articulações metodológicas e apresentando novos elementos para a construção de outras possibilidades de 


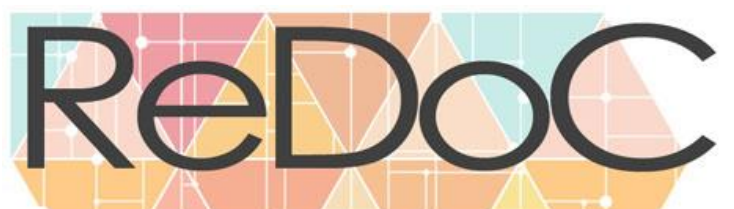

\section{Revista Docência e Cibercultura}

investigação em educação. Rivero, Martín, González e Gómez-Pablos, em La investigación participativa y colaborativa, tratam de uma metodologia para a transformação que promove a participação dos envolvidos e integra a ação educativa e social; Bravo, Pons, Moreno e Vaquero, em Investigación educativa desde la perspectiva sociocultural, consideram a natureza interativo-social dos processos psicológicos e utilizam a análise do discurso, a observação sistemática e a etnografia; Valverde-Berrocoso, Fernández-Sánchez, GarridoArroyo, Malinverni, Domínguez, em Investigación basada en deseño, abordam um modelo metodológico direcionado à criação de teorias, artefatos e práticas que apresentem soluções a problemas complexos da prática educativa; Gewerc e Vazquez-Calvo abordam, em Etnografía en la era (pos)digital, a necessidade de que o processo etnográfico considere o discurso educativo das formas multimodais de comunicação e das transformações tecnológicas vividas pela sociedade atual; Hernández-Hernández e Segarra apresentam, em Investigación (educativa) basada en las artes: genealogías, derivas y expansiones, as tensões e potencialidades deste campo de investigação e consideram que os métodos não devem ser mais relevantes do que aquilo que se quer compreender; em Trayectorias $\boldsymbol{y}$ prospectivas metodológicas para la investigación narrativa y biográfica en el âmbito social y educativo, González, Méndez, Megía e Alba abordam a investigação biográfico-narrativa cujo posicionamento interdisciplinar permite acessar o entrecruzamento de vivências que compõem a trajetória de indivíduos e coletivos; em Investigación sobre tecnologías educativas: más allá de los artefactos, Area-Moreira, Miño-Puigcercós, Rivera-Vargas e Alonso-Cano enfatizam a necessidade de se utilizar uma perspectiva interdisciplinar no desenvolvimentos de teorias e práticas de investigação sobre as tecnologias educativas e, em Ampliar miradas y compromiso de la investigación educativa con la formación de la ciudadanía, Rodríguez y Muñoz destacam como as formas de investigação afetam a formação da cidadania considerando a educação no seu sentido amplo.

$\mathrm{Na}$ diversidade de perspectivas metodológicas apresentadas é possível observar a garantia de uma possibilidade de diálogo, de articulações e complementaridades, o que de acordo com Denzin (2005) confirma a capacidade das pesquisas qualitativas em promoverem conexões entre diferentes interpretações, de modo a favorecer a construção de dados que instrumentalizem a tomada de decisões tendo em vista o desenvolvimento educacional e 


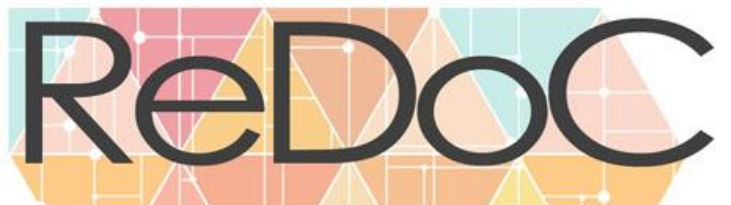

\section{Revista Docência e Cibercultura}

social. E, de forma complementar, os 11 pesquisadores envolvidos na problematização de temáticas e dilemas do fazer investigativo que compõem a Parte III - Ética, evaluación, divulgación, impacto y responsabilidade de la investigación abordam questões inquietantes às quais, frequentemente temos que responder ao longo de nossas investigações. Em Investigación ética en tiempos de algoritmos y Big Data, Montes-Rodriguez, Kushner e Ocaña-Fernández refletem acerca da relação com os participantes na investigação, do tratamento dos dados, da difusão dos resultados no que se refere a questão técnica e políticosocial; em Responsabilidad social de la investigación educativa, González-Ramírez, MuñozRepiso, Conde-Jiménez, Reyes-de-Cózar e López-Garcia problematizam a disfuncionalidade entre produção, transferência e uso do conhecimento pedagógico, colocando em destaque o compromisso da investigação e, por fim,

em Divulgación y valoración de la investigación educativa y social, Piñeiro, Mesa e Rodríguez (2020:285) os autores possuem como referência a democratização do conhecimento para além da comunicação, resolução de problemas e difusão dos resultados da investigação, com foco no compromisso social.

Normalmente, ao longo da elaboração e realização dos projetos de investigação, apresentamos o objetivo de promover mudanças educacionais e sociais, mas encontramos dificuldades em relação às reais possibilidades de que os conhecimentos produzidos sejam incorporados ao contexto educacional e social. De acordo com González-Ramírez et all (2020, p.271) o conceito de investigação e inovação responsável destaca as práticas investigativas que podem gerar uma cooperação activa entre ciência e sociedade, entre pesquisa e desenvolvimento educacional e social, o que pode auxiliar na superação dessa dificuldade quanto à pesquisa e desenvolvimento de carácter colaborativo no contexto educacional. E isso se complexifica quando tratamos dos estudos investigativos de larga escala que contribuem para decisões políticas no contexto educacional, mas que também podem apresentar equívocos morais, éticos e políticos que se amplificam com a incorporação das TIC. Montes, Kushner e Ocaña (2020, p.265) apostam em estudos de pequena escala, como decisão política e contrahegemônica, para realizar uma investigação realmente ética e democrática, pois consideram que as informações provenientes de BigData e a utilização de algoritmos podem garantir tanto maior anonimato, maior imparcialidade no tratamento das 
informações, quanto apresentar um dilema ético frente a "un mundo líquido, cambiante y 'sobredatificado"”.

\section{Considerações finais}

Essa resenha surgiu de tessituras que foram se fazendo entre a Universidade Federal do Pará, Universidade Federal de Minas Gerais, Universidade Estadual do Rio de Janeiro e Universidade de Barcelona no desejo de compartilhar novas maneiras de investigar. As conversações e indagações realizadas pelos grupos de investigação GRAOS - experiências educativas mediadas pelas TIC/UFMG, ESBRINA/Universidade de Barcelona e REUNI+D (composta por 11 grupos de investigação de 11 Universidades da Espanha) possibilitaram o encontro com uma produção que não representasse um pensamento único, mas que na sua singularidade incluísse uma diversidade de contextos, sujeitos e perspectivas de investigação educacional. Acredito que isso não apenas representa nossa concepção de mundo e de conhecimento, mas também possibilita expressarmos nossa diversidade de tal modo que possamos cotidianamente desvencilhar de nossas arraigadas relações colonizadoras.

Frente aos temas e questões abordadas em "Caminos y derivas para otra investigación educativa y social" necessitamos enfatizar a importância de que os projetos de investigação tenham um posicionamento, uma explicitação de suas bases ontológicas e epistemológicas, de tal forma que suas indagações e decisões quanto às escolhas metodológicas tenham maior clareza e coerência. De tal forma que, por um lado, possamos desenvolver uma ação transversal, que se integre à uma participação ativa dos sujeitos na estruturação, na definição das fronteiras, dos impactos vivenciados e das experiências a serem abordadas na investigação, ao mesmo tempo que se integre à dimensão relacional por meio da possibilidade de expressão dos afetos e dos vínculos que pesquisadores e pesquisados estabelecem consigo mesmo, com os outros e com as escolas. E, por outro lado, tenhamos o compromisso com a divulgação dos resultados da investigação enquanto questão ética e democrática, compromissado com os impactos e o desenvolvimento de modo a realçar a necessidade de recuperar a presença dos sujeitos, do sentido político e da responsabilidade social da investigação. 
A leitura de Caminos y derivas para otra investigación educativa y social é indispensável para quem se interessa por estudos sobre ciência e educação e, em especial, para pesquisadores que buscam diferentes perspectivas para repensar a sua investigação educacional e social. A publicação cumpre o objetivo proposto pelos organizadores e, além disso, põe em questão a difícil realidade e a necessidade de constante diálogo para que ocorram mudanças e avanços, contribuindo dessa forma para que os projetos investigativos no contexto educacional Amazônico possam se constituir em oportunidades de construção de saberes e de difusão de conhecimento.

\section{REFERÊNCIAS}

BRAZ, Saniwê Alves. Alfabetizar cantando na Aldeia Muã Mimatxi. Trabalho de conclusão da graduação em Formação Intercultural para Educadores Indígenas. FAE/UFMG, 2016 .

DENZIN, Norman. The future of Qualitative Research. In: DENZIN, Norman \& LINCOLN, Y.S. (Eds.) The Sage Handbook of Qualitative Research. London: Sage, 2005. pp.10831087.

ELLSWORTH, Elizabeth. Places of learning: media, architecture, pedagogy. New York: Routledge, 2005.

KASTRUP, Virgínia. O funcionamento da atenção no trabalho do cartógrafo. In: PASSOS, Eduardo; KASTRUP, Virgínia e ESCÓSSIA, Liliana da (orgs.) Pistas do método da cartografia - pesquisa- intervenção e produção de subjetividade. Porto alegre: Sulina, 2015.

LEVINAS, Emmanuel. Sensibilidade e proximidade. In: De outro modo que ser - ou para além da essência. Lisboa: Centro de filosofia da Universidade de Lisboa. p.81-114.

SANCHO, Juana Maria, HERNÁNDEZ, Fernando Hernández, MONTERO, Lourdes, PONS,

\begin{tabular}{r|l|l|l|l|l|l}
\hline C Redoc & Rio de Janeiro & v. 5 & n.1 & p. 259 & Jan/Abr 2021 & ISSN 2594-9004 \\
\hline
\end{tabular}




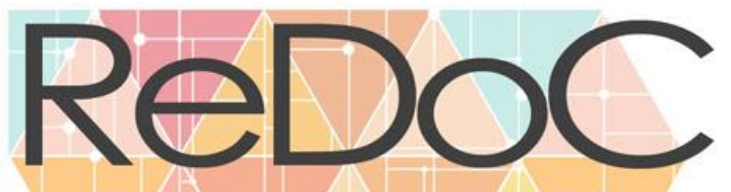

\section{Revista Docência e Cibercultura}

Juan de Pablos, FLORES, José Ignacio Rivas y FERNÁNDEZ, Almudena Ocaña (Coords.), Caminos y derivas para otra investigación educativa y social. Barcelona: Octaedro, 2020.

SEMESTKY, Inna. (2010). The folds of Experience - Constructing the pedagogy of values.

Educacional Philosophy and Theory, vol.42, N.4.p.476-488.

Este é um artigo de acesso aberto distribuído sob os termos da Licença Creative Commons Atribuição Não Comercial-Compartilha Igual (CC BYNC- 4.0), que permite uso, distribuição e reprodução para fins não comerciais, com a citação dos autores e da fonte original e sob a mesma licença. 